\title{
Challenges in the Study of Religious Values
}

\section{Introduction}

In the conduct of research, the social scientist operates with a set of principles which are guidelines for carrying out the study. These principles fulfill at least two objectives: (1) to safeguard the quality of results, and (2) to address ethical issues. The first set of objectives fall mainly within the scope of theory and methodology while the other objective has legal and ethical (or moral) concerns as its focus. Certain problems arise from the very assumptions or principles which are purported to enhance the researcher's work. The aim of this paper is to highlight some of these issues in the study of religious values with special reference to Africa and to suggest some solutions in the process.

The discussion in this paper is centered on the theoretical, methodological, and ethical problems involved in carrying out such research. Of course these are not the only types of problems faced in the field: legal, ideological, political, and practical and logistic problems, for example, remain to be solved in social research. The discussion on some of the challenges faced in the area of theory and methodology are unique to each research tradition due to their divergent philosophical and epistemological presuppositions. I hope to draw special attention to the use of modern applications of multivariate data analysis which appears to be under-represented in the study of religions on the continent. The ethical concerns seem to apply more or less to any field of research irrespective of research heritage. I hope to argue that since methodology has vital implications for theory, problems relating to suitability, appropriateness of research method, and ethical permissibility of methods should be taken into account in addition to epistemological considerations. The ethical dimension in research in particular has to attract special attention on account of its direct relationship to the harm and/or benefit of the research to participants, their right of privacy and confidentiality, their right to be informed and to consent, and the social or governmental control over the whole research process. These demands im- 
ply accountability of the researcher not only to research sponsoring agencies and to his/her own research community, but also to the local communities.

At least thirteen religious persuasions identified in Africa have been given a historical (although brief) rundown by Platvoet (1996b: 46-102). The study of religion on the continent has been concentrated on the three major ones, namely African Traditional Religions (ATRs), Islam and Christianity; but the emphasis has been on Christianity. Of late, however, a renewed interest is emerging in the study of Islam and ATRs but especially ATRs.

\section{Theoretical Challenges in the Study of Religious Values}

An important issue in the measurement of values in general is their identification. This falls within theoretical as well as methodological domains. The theoretical domain centers on finding answers to the question "what are values?", and the methodological inquires "how are values detected and measured?". These two are to a great extent interrelated and could be discussed together. But for the sake of analytical organization and clarity I shall separate them as mentioned above.

The question "what are religious values?" demands a specific religious definition. But definitions in general and for most concepts in sociology (of religion) in particular are elusive. First what do we mean by 'values'? While I cannot make any detail analysis of the concept of values in this paper, I shall give a brief description of it. Values are either limitations on, or motivations for behavior as they are contributory factor, positively or negatively, in determining human action according to the perceptions of the current situation as against what "ought" to be. (Barker, 1981:120). Put simply they are criteria for decision-making either for the individual or for the society. Hence, the value perceptions of a community in part determine rewards and punishments of its members, which help condition people to strive after those things which give psychological and emotional satisfaction and avoid those which do not.

Similar individual values together form a value system. Hence we may have a religious value system or an economic or commercial value system. Relevant to our discussion, a religious value system then would be the comprehensive system of norms or standards that guides ongoing activities, guides which source is attributed to the sacred entity being revered. A value system does not describe the values of any individual. It is the essence in which the diverse value 
sets of individuals and groups are related as complementary elements of a single system. A value system, therefore, represents the aggregate of what is expected or hoped for, required or forbidden. In the religious sense, they are a persistent web of beliefs about favorable manner of deportment ranked in order of importance (Rokeach 1973:5). Contrasting it with conduct, it is not a report of actual conduct but a system of criteria which forms the basis for judging conduct and applying sanctions. These in Albert's (1968:288) view entail operational, theoretical and functional elements.

The above descriptions of values and value systems reveal their functions in any society. In short values serve as standards for guiding ongoing activities, and value systems as general plans used to resolve contentions and to make decisions. Besides they also have motivational functions in which they have adjustive, ego-defensive, knowledge and self-actualization elements (Rokeach 1973: 14-16).

The human 'values' concept has certain correlates chief among which include norms, sanctions, needs, motives and attitudes. Are these equivalents of 'values' or not? These concepts are very much closely related to "values" and reference to them are often unavoidable in the explanation or description of specific "values." The problem arises in identifying the relation between these concepts and the concept of "values". This is where care should be taken. It is necessary to understand the differences and links between values, norms or rules, and sanctions or controls, for example. While values in a culture stand for the peoples' goals or objectives in their life, the norms are the regulations/rules they are enjoined to adhere to in order to achieve their values. The sanctions on the other hand constitute the means by which members of the particular community make sure that every one in the group will follow the proper values, respect and observe the governing norms. Also although many particular motives may reinforce commitment to a given value they cannot be taken as their equivalents.

The definition of religious values depends on the epistemological orientation of the researcher in relation to his/her view of religion. The study of religion and religious orientations in Africa has over the years been carried out by both theologically inspired scholars of religion and anthropologists, but of late sociologists and psychologists have joined the task each peddling their disciplinary perspectives and world-views which color their work and specifically the definition of religion. Those, like some scholars of religion, who see religion as fulfilling sacred and cosmological needs, thus emphasizing the sui generis, or the "intrinsic value" nature of religion would define it in substantive terms. On the other hand those who, like most sociolo- 
gists and social anthropologists, secularize religion viewing it in terms of societal needs, functions and control, would define it in functional terms. This has been the historical tendency in the social sciences in explaining indigenous religions of Africa in particular. The above discussion shows, therefore, that the pick between a "substantive" and "functional" view of religion, whether African or otherwise is based on the individual researcher's perspectives and concerns.

The functional view is especially stressed when it comes to assessing conversion from ATRs to Christianity in Africa. This is often represented as having economic overtones (Hopkins 1970:46; Meyer 1995), instead of emphasizing a genuine change of religious affiliation, or the possession of a subjective religious perspective. Often social psychological paradigms such as relative deprivation (RD), and its close associate, social comparison, are utilized to explain the spread of Christianity in Africa. ${ }^{1}$ Hopkins, for example, made use of "learning and role conflict" theories to conceptualize and interpret his point of view (1970:53). His arguments derive from the need for recapturing the perceived deprivations and loss of security experienced in traditional societies, with the expectation of rewards through links with Europeans (1970:47). In this way recruitment into the new Christian community is seen in terms of socioeconomic indicators, discounting personality factors. Although use of this theoretical perspective was dominant from the 1950s to mid 1980s, traces of it are still detected today among some authors who use it to categorize the religious inclinations of Africans. An illustration of this is found in Meyer (1995) who attributed the preoccupation of "most" Ghanaians in the correlation between evil spirits and financial problems to economic deprivation. More on this under "Ethical Challenges" below.

The challenge posed to the researcher in the field of religious studies, therefore, is to delineate religion in a cogent conceptual framework which would form a suitable basis for a research project. A second concern is the balancing act so that the sociological inquiry does not turn into a deterministic venture where the religious phenomenon is interpreted on the basis of socioeconomic factors. In the end this means the researcher needs to develop a theoretical working definition of what religion and religious values are, ready for confirmation or refutation in research.

Not only the applicability of categories but also theoretical formulations developed in European contexts need to be re-examined, for example, the application of the "secularization" (and laicization), and

${ }^{1}$ See further elaboration on this in Asafo (1997). 
the "rational choice" theories dominant among sociologists of religion in the 1980s and 1990s respectively. Although there is no easy way out of these problems it is important to be articulate in the choice of language and categories as well as theoretical concepts in conveying our findings about the cultures we study.

\section{Methodological Challenges in the Study of Religious Values}

Basically, there have been two main research approaches used in religious studies. These are the qualitative and quantitative methodologies. Qualitative research is the research tradition mainly employed especially by ethnographers and historians, in data collection and analysis. This research tradition is distinguished by five main intellectual perspectives which provide it with its distinct epistemology. These are phenomenology, symbolic interactionism, verstehen, naturalism, and ethnogenics. There are a variety of approaches under this tradition today but the three main methods normally used are: participant observation, unstructured interviewing, and life history. One can also find the increasing use of the group discussion and the phenomenography methods. The group discussion approach is a combination of observation and conventional unstructured interviews, organized in a group discussion format. Phenomenography is applied particularly in analyzing how people perceive phenomena. It has been used mainly in the confines of educational perception. This approach is equally suitable to be used in obtaining perspectives on religious orientations. It falls into the confines of post-modern radical empiricism which "aims to describe accurately and in such detail the experiences of the people under study that outside readers are able to enter those experiences" (Bourdillon 1996:145).

Quantitative analysis on the other hand builds on applied mathematics. Researchers using this method have a range of specialized, standardized set of data analysis techniques to choose from. These are usually statistical techniques relying these days more and more on computer programs such as Statistical Package for the Social Sciences (SPSS), Biomedical Programs (BMDP), Statistical Analysis System (SAS), and Minitab. The use of this method requires manipulation of numbers that represent empirical facts in order to test ab-

${ }^{2}$ I am not able to discuss each of these methodological positions in this paper. The interested reader may refer to Bryman (1988), and Ritzer (1992). 
stract hypotheses with variable constructs. This empirical data is acquired through survey questionnaires, and normally transformed into numbers, which stand for values of variables used to measure characteristics of subjects, respondents or other cases. The symbolic language of statistical relationships between variables is used to discuss or establish 'causal' or correlational relations. It is assumed that social phenomena can be measured and or quantified using numbers and when manipulated according to the laws of statistics, the numbers reveal features of social phenomena. This mode of investigation is favored mostly by sociologists of the positivistic-naturalistic inclination in contrast to the humanistic-culturalistic legacy. The positivistic-naturalistic group asserts that the social sciences are basically similar (methodologically) to the natural sciences. For this reason the same kind of reasoning, method, and explanatory role were to be applied in the social sciences as in the natural sciences. On the other extreme pole are the humanistic-culturalistic camp who deny any similarity between physical events such as those investigated by natural scientists and man's social actions, which is the center of investigation in the social sciences. The old confrontational line still exists on the question of whether it is appropriate or even desirable at all to subject social phenomena such as religious values to investigation using methods applied by natural scientists. The challenge confronting the researcher in this line of work is to determine how far to go with the use of sophisticated statistical/mathematical approaches to the research. While one should be careful in recommending a strictly high-constrain statistical approach to the study to such human phenomena as religious values, more light may be shed by the use of at least descriptive statistical methods.

Broadly speaking, the methods of social research may be divided into three categories. These stand for the different ways in which the data are secured: (1) experimental manipulation, (2) questioning of respondents, and (3) direct observation (Kelman 1982:68). Each of these main categories has been subdivided into three groups ending up in nine types of research methods. See table 1 for details.

Experiments and manipulations lie outside our field of study but are found mostly in the natural sciences and some sections of psychology and, therefore, would not be treated in this paper. In the context of our present discussion our concerns are mainly in the confines of the last two categories: questioning of respondents, and direct observation. As mentioned above the study of religion and religious orientations in Africa has been pursued by both theologically inspired scholars of religion and anthropologists, sociologists and psychologists. These researchers carry out their work with these two types of 
research frame of reference. Within these bounds it is argued that the phenomenological and comparative historical approaches in respect of the study of religions in Africa with special reference to ATR should be encouraged in place of the hitherto theological and socialfunctional strategies (Olupona 1991). The phenomenological perspective is a dual procedure in which there are (1) morphological, and (2) hermeneutical phenomenology (Benneman, jr., et al, 1982:14). The normal mode of approach has been surveys and interview studies, records and secondary analysis, unobtrusive public observation, and participant observation.

Table 1. Categories of Research Methods

\begin{tabular}{||l|l|l|l||}
\hline $\begin{array}{l}\text { TYPE OF } \\
\text { RESEARCH }\end{array}$ & \multicolumn{3}{|c|}{ S U B C A T E G ORY } \\
\hline $\begin{array}{l}\text { Experiments } \\
\text { and } \\
\text { Manipulations }\end{array}$ & $\begin{array}{l}\text { 1. Laboratory experi- } \\
\text { ments and } \\
\text { simulations }\end{array}$ & $\begin{array}{l}\text { 2. Field } \\
\text { experiments }\end{array}$ & $\begin{array}{l}\text { 3. Organizational } \\
\text { and social } \\
\text { experiments }\end{array}$ \\
\hline $\begin{array}{l}\text { Questioning of } \\
\text { Respondents }\end{array}$ & $\begin{array}{l}\text { 1. Questionnaires and } \\
\text { tests }\end{array}$ & $\begin{array}{l}\text { 2. Surveys and } \\
\text { interview studies }\end{array}$ & $\begin{array}{l}\text { 3. Records and } \\
\text { secondary } \\
\text { analysis }\end{array}$ \\
\hline $\begin{array}{l}\text { Direct } \\
\text { Observation }\end{array}$ & $\begin{array}{l}\text { 1. Structured } \\
\text { observation }\end{array}$ & $\begin{array}{l}\text { 2. Unobtrusive } \\
\text { public observation }\end{array}$ & $\begin{array}{l}\text { 3. Participant } \\
\text { observation }\end{array}$ \\
\hline
\end{tabular}

Each of the categories of method mentioned above has both technical, epistemological and ethical issues to contend with. The ethical dilemmas are deferred until when I discuss ethical problems later. For now we shall highlight the technical and epistemological challenges associated with the two main research traditions. These problems center around (i) Reactivity and the lack of Ecological Validity (ii) Verstehen and interpretation, (iii) Theory building, (iv) Validation, and (v) Poor representativeness and generalization.

(i) Reactivity and the lack of Ecological Validity

Despite differences between the quantitative and qualitative traditions of research both have similar technical problems. Chief among these are "reactivity" and the lack of "ecological validity", also known as "demand characteristics" in psychology, due to the unintended influence of the researcher's personality (age, race, gender, educational 
status, etc.), and his/her research equipment and instruments. These may create a variety of undesirable results in that people's behavior or responses may not be actually their normal behavior or views. Conversely, the issue is one of "researcher reactivity" or "researcher bias", otherwise called "experimental reactivity" or "experimental bias" in psychological studies (Rosenthal 1976). It may be suggested that, in order to secure natural behavior, the researcher must be uninvolved.

Validity in scientific research "refers to how well a study, a procedure, or a measure does what it is supposed to do" (Graziano \& Raulin 1993:60). In other words how accurately an indicator measures a construct under study. The lack of "ecological validity" can be seen in the sensitivity to slight changes in wording and the un/availability of the necessary knowledge to answer a question on the part of the respondent. Therefore, the question is how best the researcher's instruments capture the daily life, conditions, opinions, values, attitudes, and knowledge base of those being studied as expressed in their natural habitat. This kind of problem is particularly common and pronounced in religious research. Furthermore, this situation is further complicated by the fact of social desirability on issues as most interview reports are personally reported intentions of interviewees which may really not describe their actions. Often respondents belonging to religious groups would like to prove their unfailing loyalty to, and solidarity with their group by giving insincere responses to sensitive inquiries. Sometimes these perceived sensitive questions are avoided. In questionnaire situations in quantitative research they are not answered at all and thus creating the problem of missing values during analysis. Often the avoidance of sensitive questions may be traced to about three (or possibly four) sources: mistrust and/or, fear, agnosticism, and carelessness. With these considerations the data collected may be rendered "ecologically invalid."

As a solution to this problem Bourdillon suggests the involvement of participants in the collection of data, a practice which may be considered to reduce this situation. But often even "insiders" such as rulers, priests or even individual believers may misrepresent the dominant view in a particular community in the case of qualitative research (Bourdillon 1996:140-141;). A detail procedure such as involved in the "analytic induction" and "grounded theory" approaches may minimize this misrepresentation (cf. section on "Problems with theory building" and "Poor Representativeness" below). Furthermore, solutions may be found, or the incidence minimized by planning the research project to include a pilot phase (that is, finance permitting) when such methodological problems and others may be detected and 
resolved before the main research. During this time too trust could be forged between the community and its leaders, and the researcher. This is to be done through the same strategy of rapport building by making the interviewees know why the research is being conducted and its benefit to them. Although "reactivity" and "ecological validity" are not restricted to any one research technique, it is much more pronounced in qualitative than in quantitative research.

A related problem in quantitative research is Reliability. This is the ability of a set of indicators of latent constructs to be consistent in their measurement. In other words, it is the degree to which a set of indicators "contribute" to the measurement of a construct. While reliability does not guarantee validity and vice versa, they are two separate phenomenon but inter-related conditions. A measure may be accurate (valid) but not consistent (reliable). The two together or separately often result in a further problem of measurement error, to be discussed later.

(ii) Verstehen and Interpretation/Explanation of Human Action

Social science strives to explain human action which in its broadest sense means "meaningful behavior". It is not always certain whether a man's behavior is intentional or not because both (as in the case of the source of morality) the internal and external causes of a specific act are often complex and obscure. Among the various questions that arise from this realization is how the social scientist should understand and explain man's "meaningful" behavior? Should his/her task be the causal explanation of such action on an individual or social basis? Should the explanation be "subjective" or "objective"? That is to say should the explanation of human action follow the methods of the naturwissenschaften (the natural sciences) which seek to explain objectively observed phenomena by means of general laws (pro positivistic-naturalistic), or should it rely on the faculty of verstehen or understanding (pro humanistic-culturalistic)? For the humanisticculturalistic proponents, since the social or cultural sciences are of a character basically and radically different from that of the natural sciences, there is the necessity for the concern for the subjective states of men. This is the concern with understanding and interpreting men's motives and cognitions. This brings in the discussion on Verstehen, or "understanding". The central issue in this verstehende sociology is the idea of "objectivity" or "Epoche" (the suspension of normative judgment) in the explanation and interpretation of human action including religiously motivated behavior. The arguments for and against this philosophical basis of interpretation since Max Weber's time have been treated well now and again in the literature 
(Truzzi 1974:1-2; Brodbeck 1968; Bourdillon 1996). Researchers who have taken the non-aligned position and suggesting different ways of understanding this concept have also emerged (Cox 1996).

The dominant hallmarks of qualitative research are physical nearness to the entity under investigation: direct face-to-face interaction between the researcher and the entity being investigated in their environment; and the insistence on taking the informants' perspectives. In this, consideration is given to the events, actions, norms, values, etc. which, in the researcher's objective view, is permissible or appropriate in the context of the perspectives of the participants in that social setting. This is a laudable objective and needs to be emulated by quantitative researchers when dealing with African cultures, despite the problem of the ability of the researcher to perceive and interpret events and phenomena as do his/her sources due to background differences between the researcher and the respondents. This shortcoming may be made up for by the application of what is known as the triangulation of measurement method. This is a methodological approach whereby some of the shortcomings of structured questionnaire survey are catered for by the inclusion of open-ended questions, thus giving the respondents opportunity to express their views freely in their own words. This gives much more substance to otherwise sometimes "dry" mathematical/statistical "explanations" encountered in most quantitative research.

Arguments for the application of verstehende methodology seem appealing in certain respects but unworkable in others as many sociological propositions are. It is not evident that an investigator cannot explain human action unless he/she has experienced him/herself the psychic states he/she imputes to them, or unless he/she can successfully recreate such states in imagination. Is it to be taken, for example, that a sociologist has to go through the psychological processes leading to suicide and then commit suicide before he/she can understand why people commit suicide under certain conditions? Granted that the investigator has experienced these psychic states or reproduced them, his/her explanation could still be far off the mark simply because he/she is a unique personality different from the person or group of persons whose actions he/she is observing. For example, it is possible to "know" that a believer who endows his/her estate to his religious organization has the love and welfare of his/her religious organization at heart, or has done so for fear of his/her god, without the researcher experiencing or recreating such love, or fear in him/herself.

Generally, it is accepted that the social sciences (sociology in particular) attempt the interpretative understanding of social action in 
order to arrive at a causal explanation of its cause and effects. Explanation requires a grasp of the complex of meaning in which an actual cause of understandable action thus interpreted belongs. The method of verstehen alone, therefore, cannot do justice to the comprehensive explanation or understanding of human actions particularly in the field of religion, a subjective phenomenon. Greater service could be rendered if applied in conjunction with the other modes of interpretation, i.e., the covering-law forms, very much favored in quantitative inductive/deductive-statistical and deductive-nomological analyses.

In relation to the study of religions in Africa the apparent crossing of ideological boarders is necessary not only in the research methodological traditions but also between academic disciplines. This seems to be the dominant view in the research community today (Olupona 1991; Platvoet 1996; Bourdillon 1996:140). Platvoet's (1996:118) conclusion is that the use of the multidisciplinary approach to the study of religions in Africa, a view point which combines anthropological, historical, phenomenological, comparative and other religious studies approaches, yields better results. Olupona (1991:3) contends that this "will provide us with a more accurate interpretation of the essence of African religious beliefs and world-views". He alleges signs of this are already emerging in the research community concerning the study of African traditional religions, citing Hacket's commendable style of amalgamation of the historical approach with the sociological in the study of the religious environment in Calabar (Nigeria). I however, concede the fact of some problems with inductive-statistical explanations which should be avoided.

(iii) Problem with theory building

A feature of qualitative research is the need for relevance (Holme \& Solvang 1991:105ff.): relevance relating to both the researcher and the actor under study. ${ }^{3}$ Researcher relevance among other things deals with whether the result develops new theoretical knowledge and more useful understanding and models. Actor Relevance on the other hand deals with praxis. ${ }^{4}$ This element examines the usefulness of the information and the resultant theory building for better under-

3 Other aspects of Researcher Relevance are: (1) what value direction the result has; and (2) the understanding value the result has.

${ }^{4}$ Additional elements of Actor Relevance deal with procedure or description; provocation: the importance to create reaction with the entity being investigated; self-experience: the extent to which the researched entity cooperates so that the actor gets a better understanding of and consciousness about him/herself. 
standing of, and change of praxis for the entities being investigated. The question is whether in our bid to measure religious values our intention is to develop a theory, and if so when does one begin formulating such a theory?

In order to bring these problems to manageable limits, many researchers today (especially those in the qualitative tradition) emphasize the generation of theories rather than just trying to test already formulated theories and concepts as prevalent in quantitative research. To enhance a better linkage between theory and investigation, several approaches have been developed. Two of the most frequently cited approaches today are the analytic induction (Bryman 1988), and grounded theory (Glaser and Strauss 1967; Strauss 1987; Strauss and Corbin [eds.] 1997) as a means of generating theory which is embedded in data, and also as a procedure to avoid the formulation of theories and concepts in advance of beginning field work. This is in order not to impose a potentially foreign framework on target societies or institutions through whose perspectives ethnographers (and sociologists) insist they want to view the social phenomenon; and also because there is "the possibility of introducing a premature closure on the issues to be investigated, as well as the possibility of the theoretical constructs departing excessively from the views of participants in a social setting" (Bryman 1988:81). This calls for strategies which are relatively open and unstructured and in which the formulation and testing of theories and concepts proceed at the same time as data collection.

(iv) Poor Representativeness and Generalization

One main limitation in low-constrain methods of research, to which belong case study and naturalistic observation is poor representativeness. The problem associated with the reliance on a single case (be it a school, a community, a firm) poses a challenge of how far it is possible to generalize the findings of such research. One cardinal element of the problem is the representativeness of the case study findings to all the members of the population from which the case was selected (Graziano \& Raulin 1993:132). The concern to see through the eyes of one's informants in qualitative research raises the need to address the question of the typicality of the eyes through which he/she is seeing. This in itself is an indication of the use of an appropriate framework to the investigator's mode of research. An example is the advice offered by Glaser \& Strauss (1967) on the pref- 
erence of theoretical sampling ${ }^{5}$ over statistical sampling. The theoretical sampling approach alleviates the predicament of the representativeness of the eyes.

Three further possible solutions to this dilemma have been suggested by Bryman (1988:88-90). First the researcher may study more than one case (the comparative approach). Secondly a number of cases may be examined by more than one researcher (the team-cumcomparative research approach), and thirdly, to seek a case which is 'typical' of a certain group of characteristics. Finally, a time series (longitudinal) approach to research is recommended, in which series of detailed interviews over a long period of time are conducted, instead of a one time short survey interview in which respondents give responses without giving much thought to it. There is also the need for a thorough and proper reconstruction of historical sources of the research material through proper "source criticism". This may take care of not only the nuisance of inadequate symbolism but also of reliability (Platvoet 1996:116). It is evident that in the past, views on African religiosity normally represent those of the ruling or upper classes, as earlier information was primarily collected from such classes of the African society (Westerlund 1993:58-59). Just as European missionaries of the first and early part of the second of the four Christian missionary periods in Africa (1444/45-1790; 1790-1840; 1840-1890; and 1890-1960) concentrated on the ruling classes, so did the anthropologists and early historians and churchmen who researched and wrote on African culture and religion.

An aspect of the poor representative conclusions on religions in Africa has been the unreliable statistical data on the distribution of religions on the continent. Few would deny the fact that empirical data in this discipline is awfully atypical and undependable often illustrated by unacceptable levels of margin of error in figures presented in the literature on religions on the continent. For example, statistics provided by prominent writers like Barrett (1982:782) have been seriously contradicted by Folala. ${ }^{6}$ Also conclusions reached by Mandivenga (1991) based on Folala's figures, although similar to the trend in change of religious affiliation as presented by Barrett has been

\footnotetext{
${ }^{5}$ In theoretical sampling, in order to address the question of the adequacy of sample, the researcher observes only as many activities, or interviews as many people, as are needed in order to "saturate" the categories being developed, and then moves on to the next theoretical issue and repeats the same process.

${ }^{6}$ Folala's (1988:11) conclusions cited in Pobee (1991:58).
} 
questioned in some other quarters. ${ }^{7}$ In the area of empirical (statistical) religious study there seems to be a gross lack of the scientific urge in response to a fair sense of representativeness. The challenge, therefore, to the researcher on religions in Africa is to move more towards a research which has a resemblance of the scientific approach instead of guesswork and approximations. One way of solving this difficulty may be through the direct action of the research community. Researchers should make the conscious and candid effort by way of symposiums when and where such theoretical and methodological questions, which cannot be solved easily by any one researcher by him/herself acting alone, would be identified. Then the community as one voice could confront national governments to include such information in their national population censuses, if held at all. But first the national governments have to be convinced that the inclusion of such information on religion in their censuses can also be of benefit to their countries. It is clear that some nations on the continent have deleted questions on religious affiliation and practice from their population census questionnaires. This only contributes to the already confused nature of the study of religions on the continent, at least the quantitative sense.

\section{Identification of Religious Values}

With the identification of values comes the age old puzzle: "how do we know whether we are identifying or measuring values and not attitudes?" Or put differently, "are social scientists not taking attitudes for values in their social investigations?" Attitudes as Thurstone (1959:216) describes it is "the sum total of a man's inclinations and feelings, prejudice or bias, preconceived notions, ideas, fears, threats, and convictions about any specific topic." This reveals the subjectivity and personal nature of attitude. Irrespective of these characteristics "attitude" should not, according to Thurstone, disqualify it from being used as a scientific measure due to the availability of opinions which are one's expressions, verbal or written about an attitude. ${ }^{8}$ Opinions serve as symbols of attitudes. Therefore, in order to

\footnotetext{
7 This was contained in a correspondence I received from Arvi Hurskainen, the editor of the Nordic Journal of African Studies in April 1997.

8 Thurstone $(1959,216)$ restricts "opinion" to verbal expression which we deem not wholly adequate. Written expressions could equally describe one's attitude since an opinion, verbal or written symbolizes an attitude. Of course if someone has written a statement it could equally be referred to as what he/she "said".
} 
measure attitudes one could use opinions despite its limitations, ${ }^{9}$ especially that of trustworthiness because of the problem of reactivity innate in field research.

The discussion on the operationalization of psychological/sociological concepts may not be complete without the mention of the inclusion of background factors such as if the respondent had been brought up in a religious home, and the perceived religiosity of parents or adult guarantors, in the whole research process. It is generally agreed that childhood experiences often have serious implications for adult life. For that matter while designing a research questionnaire or formulating a research proposal, this should also be considered.

A significant aspect of a culture is language. The identification and study of religious values, therefore, involve the content analysis of the suitable verbal as well as written material of the religious heritage. This is made up of the community's traditions (oral and written) and folklore: folktales, riddles, wise sayings, etc., which may constitute a mass of ideological material. This category is equally necessary and important as its identification reveals implicit assumptions in social discourse which in turn uncovers values not otherwise readily observable. In more literary societies where religious thought has been preserved in written form one of the usual ways is to rely on literary texts-holy books and/or other literature--that spell out the belief and ritual systems of the said religion. For example, the Bible for Christians, the Qur'an for Muslims, the various Vedas for Hindus, Tripitaka for Buddhists, or the Book of Mormon for Mormons. Relying on texts in the interpretation of religious values poses a special problem in identifying the religious values in ATRs in this manner for lack of coded text. ${ }^{10}$ On the other hand Platvoet (1996:116) has found two major virtues (a high degree of contextualization and representativeness) in the study of the history of religions of Africa despite the lack of religious texts.

Even the study of coded religious traditions on the continent such as Christianity and Islam poses other measurement challenges due to certain ingrained cultural and/or ideological realities. Examples of these include the near peculiar translation and interpretation of foreign (particularly English) words such as "religion" into African lan-

9 For a discussion on the limitations involved in using 'opinion' as an index of attitudes, see Thurstone (1959:215-219).

10 This should not, however, be construed as the usual excuse advanced by "Western scholars to deny the existence and authenticity of African history", in this case the history of African religions. Cf. Platvoet (1996:115-116). 
guages due to their historical evolution. This may be illustrated among the Ewes of south-eastern Ghana with the etymological development of the two contrasting sacred entities: Mawu for the Christian "god" and Abosam for the "devil", and the resultant or accompanying meaning given to the idea of religiosity (Meyer 1992). It has been found in my own research that the Ewe idea of religiosity is accorded only to Christians and not to any other religious community. This is due to the etymology of the Ewe word Mawusuborsubor, and translation of this word from English into the Ewe language. To avoid this kind of enigma care, therefore, has to be taken in the translation of foreign language questionnaires, and prior knowledge of even the ideological basis of linguistic terminologies and expressions is vital. A significant issue is the use of questionnaires in regions for which it was not originally designed, without due revisions to suit the ideological view points prevailing in the area. It is important to revise such research instruments to take into account cultural and ideological conceptualizations in order to give a more meaningful explanation of the belief contents of the people if in-depth interviews are impossible.

Adopting other Methodological Approaches: The case of Multivariate Data Analysis

Although research on religion in Africa is carried out either in the form of questioning of respondents or direct/participant observation, the subcategory of questionnaires and tests, and structured observations are minimal. Equally important to be encouraged should be the quantitative approach in the form of questionnaire data. This is not to say this strategy is of any superior significance but its increased use may fill the statistical void that has been created by its little use. Inglehart (1990:130) insists that despite its curtailed adequacy, there are some indispensable advantages in using this quantitative approach to the study of religion: (1) It is a means of obtaining vastly larger sample size than one could obtain with in-depth interviews; (2) Moreover this is essential if the objective is to make reliable intergenerational comparisons or control for social background factors; (3) the mass survey, as done for example in the European Values Survey over the past ten years, can provide representative national samples - something extremely useful if one wishes to know what is happening to a society as a whole or to analyze phenomena in cross-national perspective; and (4) the public opinion survey has been a proven approach which has been found to be quite accurate and reliable for many purposes. 
Furthermore, the use of the quantitative approach and relevant techniques such as found among multivariate data analysis, e.g., Structural Equation Modeling (SEM), helps bring out vividly, by mathematical manipulation the underlying structural relations among the various dimensions of the religious orientations and social concerns. For example, one may want to know how religion relates to differences in socioeconomic status in society, its relationship to technological changes, e.g., on issues like health (the AIDS epidemic and in what circumstances religion might put sway on sexual practices and promiscuity, or birth control issues, alcohol consumption and/or abuse, etc.), agriculture, education, and religion's role in social conflict and peace. Qualitative approach as championed by radical empiricists may deal with such issues but falls short of giving us how widespread and typical these views are, which is of immense importance for policy makers. In other words theories generated through isolated case studies by the use of qualitative method need to be reevaluated in order to see how widespread the views expressed are in the community. This can be done more appropriately through sociological studies of religion relying more on multivariate data analysis. Bourdillon (1996:147) observes, and quite to the point that "The artistic impressions of radical empiricism may on occasion speak to such issues but we also need to know how widespread these impressions remain valid: we need to do some counting."

One, however, encounters some drawbacks in their operation, not the least as it is heavily theory driven. It is used mainly as a procedure of theory testing and confirmation, a criticism qualitative researchers are quick to point out. But this need not be so because statistical models can also be used as excellent means of, not only theory testing and confirmation but also theory generation, just as qualitative approaches like analytic induction and grounded theory mentioned earlier, if properly applied.

Besides, the application of this method requires the use of modern machines particularly powerful computers and the appropriate statistical computer programs, not to mention the special skills involved in working with them. It is evident that research projects of this type are poorly represented in the literature of the study of religions and religious values on the continent. If it is the lack of resources such as computers and their paraphernalia, African governments should be pressed to see the importance of such equipment in the academic pursuits of both students and teachers, and should be encouraged to provide them. On the other hand if the deficiency is due to undeveloped relevant skills, reflecting inadequate curriculum content, the university authorities should be made aware of the need so that 
where this is wanting syllabuses in such universities would be revised. An attempt in this direction is under way in some universities by way of offering more detail methods courses to students. But this seems inadequate as much of it concentrates on the qualitative legacy.

There are at least eleven different varieties of multivariate techniques to choose from. I shall not burden the reader with all of these in this paper. ${ }^{11}$ The choice of a particular technique is determined by the objective and theoretical direction of the research. Each of these follows a structured approach of six steps in multivariate model building, except Structural Equation Modeling (SEM) commonly called LISREL (one of the more popular computer programs used for it), which goes through seven steps and is unique to SEM (Hair, jr., et al, 1995). SEM examines a series of dependence relationships simultaneously, unlike other multivariate approaches. Its widespread use is traced to its two most important strengths: (1) while it allows a straightforward method of dealing with multiple relationships simultaneously with statistical efficiency, (2) it also has the ability to appraise the relationships thoroughly, thus providing a shift from exploration to confirmation analysis (Hair, jr., et al., 1995:617). Hence, SEM has an added advantage in that it is a simultaneous factor, multiple regression and path analyses. The seven steps involved in SEM are (1) developing a theoretically based model, (2) constructing a path diagram of causal relationships, (3) converting the path diagram into a set of structural equations and specifying the measurement model, (4) choosing the input matrix type and estimating the proposed model, (5) assessing the identification of the structural model, (6) evaluating goodness-of-fit criteria, and (7) interpreting and modifying the model.

Model equations are in two parts: the Measurement Equation, and the Structural Equation. The Measurement Equation is that part of the model where we see the relationship between the dependent variables and the observed variables. The Structural Equation is the reset of the model where there are only the structural relationships among the unobserved (latent: dependent and/or independent) variables. These equations, according to step 3 of the SEM process, are specified either in mathematical (regression) equations or in Lisrel special formulations (notations). Often the third step is skipped by researchers, for this is taken care of later in steps 5 and 6 by the computer program. The critical points in the model building using

${ }^{11}$ Interested readers may consult the following from which further reading lists may be obtained: Hair, jr., et al., (1995); Hoyle, (ed.) (1995). 
the SEM technique are steps 5 to 7 . It is at these points that special attention is to be paid to the operational assumptions mentioned below.

In the use of multivariate data analysis the researcher cannot avoid the use of certain basic terms. Assumptions in this type of analysis are based on such terms as dependent and independent variables, latent and observed variables, error terms, and parameter coefficients, variances and covariances, to mention a selection. Operational assumptions inherent in the notion of "cause" within the framework of variable analysis include the absence of specification error, identification problem, measurement error, and assumptions dealing with error terms (Lewis-Beck 1980:26-30; Hoyle 1995:1-15). Using this research approach is not an easy way of presenting the religious inclinations of respondents. It has its peculiar drawbacks and difficulties. But there is the need to re-assess the hitherto overemphasis on the qualitative approach to the detriment of its quantitative counterpart. Some matching is overdue.

\section{Ethical Challenges in the Study of Religious Values}

In the work of the social researcher there is always the presence of moral dilemmas which need urgent attention. This plight "has the very real potential for violating the conditions of human freedom and is that it takes place at an intersection of ethical and epistemological systems, thereby posing unforeseen moral dilemmas for the anthropologist" (Appell 1978: ix). Appell's comments certainly do not apply to the discipline of anthropology only. Much can be said of all social investigation. It is important to be aware of the ethical dilemmas and pitfalls associated with social research.

The requirements of these predicaments demand that researchers thread the delicate line between the scientific requirements of methodology and the appropriate human relations (rights and values) that face the potential threat posed by the research (Kimmel 1988:9). This calls for underlying guiding research principles in order to proceed both ethically and without putting into jeopardy the validity of the research project as far as possible. Four broad ethical principles are invoked in the study of human participants: (1) autonomy/selfdetermination, (2) nonmaleficence, (3) beneficence, and (4) justice (Beauchamp, et al., 1982:18-39). These principles form the bases of the dilemmas facing the researcher. In that regard the researcher is continually faced with the question: "how can I conduct myself ethi- 
cally and still have headway through sound and generalizable research?"

Ethical problems may be classified according to the level of the research process where they show their implications most clearly. These include treatment of research participants/respondents, responsibility to society, and integrity in the collection, analysis and reporting of data. The difficulties are also wide ranging with certain characteristics. In Kimmel's (1988:30-36) judgment, the source of ethical problems is conflicting values, and the complexity of a single research problem can give rise to multiple questions of proper behavior. Judgments about proper conduct lie on a continuum ranging from the clearly unethical to the clearly ethical. He supposes that an adequate understanding of an ethical question sometimes requires a broad perspective based on the consequences of research, and that though sensitivity to ethical issues is necessary this realization is not enough for solving them. Furthermore, dilemmas relate not only to the conduct of the research but also to the subject matter as well. Finally while ethical issues involve both personal and professional elements, it can pertain to science (as a body of knowledge) and to research (conducted in such a way as to protect the rights of society and research participants). An irony in this area is that an ethical problem can be encountered as a result of ones decision to conduct or not to conduct a specific study.

There are a range of ethical issues which have bearing on the measurement of human values (including religious ones) which raise difficult moral dilemmas. Essentially ethical dilemmas are linked to, and arise from the various categories and subcategories of research methods mentioned earlier (Kelman 1982:69). These dilemmas cover particularly the harm and benefits of social research to participants, their right to privacy and confidentiality, their informed consent and the social control of the findings of the research (Boruch and Cecil, eds., 1983; Beauchamp, et al., 1982). These issues have untold impact on the concrete interests of participants, the quality of interpersonal relationships and the wider social values. Taking the impact on the wider social values, for example, is the presence of diffuse harm, (i.e., the perversion of the political process, manipulation, inequality, arbitrariness); reduction of private space and erosion of trust (e.g., cynicism and anomie).

Another vital issue to be mentioned here is the issue of accountability (Riecken 1983:9). There are two kinds of accountability: (1) accountability of an agency sponsoring research for the way in which its funds have been spent. Corollary to this is the accountability of the researcher to discharge his/her contractual responsibility to the 
agency: how honest has been the performance of the various research tasks? (2) researcher's accountability to his scientific colleagues. In this regard one has to inquire continually of him/herself: "have I fulfilled my tasks in a well recognized scientific manner with enough data to disclose, and details of procedure to allow competent peers to verify my performance?"

The researcher is not only responsible to his/her research community but also specifically to the community studied. True to the philosophical bias of their disciplines, Western researchers (not the least over represented are Anthropologists) all too often descend on African communities treating them as guinea-pigs in a scientific laboratory. While this is done sometimes with the best of intentions, it is at other times done nonetheless to the point of misuse, exploitation and misrepresentation resulting in the diffuse harm pointed out above. Meanwhile the researchers harvest huge benefits in the form of money, fame and academic credentials (Njinya-Mujinya 1996:120121). The challenge usually arises during the analysis and interpretation of the materials obtained in the field study. Often observations in the African setting are erroneously presented as not matching up to certain pre-set European/Western criteria (Lewis 1990:313-314). This is not uncommon even in the study of religions in Africa. ATRs in particular are viewed as being full of superstition and magic (Murphy 1990:323-324); and often accorded the stigma of "primitivity", as though similar manifestations and practices are not found in Europe and the rest of the Western world. This indirectly reveals the ethnocentricism of such writers some of whom may be unaware of it. It is important therefore, that the researcher on Religions in Africa should allow the phenomen on a level playing ground as offered to other religions and regions of the world. While it is necessary or even important to make comparisons sometimes in research, it is equally necessary avoiding using preset standards. The religious phenomenon in Africa should be understood, respected and accurately presented in its cultural context. The imposition of the norms and values of the researcher's own culture should be deceased from, absolute "neutrality" should be encouraged towards all and any beliefs or the academic establishment.

A prominent although often ignored problem is the question of respondent validation. Respondent validation is the practice whereby ethnographers submit a version of their findings to the objects of inquiry for feedback. The difficulty here lies in the nature of the relationship between the researcher's data, which is the interpretation of his/her informants' world-views, and the elaboration of those data as a report for academic audiences. A significant aim of research should 
be the advancement of knowledge, which would be put to good use to better the conditions of the society which has been studied. For that matter it is imperative that the society in which the study have been conducted should be informed about the scientific findings about them.

One way of making the informant-researcher communication complete is to establish information banks in rural Africa as suggested by Njinya-Mujinya (1996). This would go a long way to satisfy the "respondent validation" requirement in research. Njinya-Mujinya's suggestion, if taken seriously would benefit not only the research community but also the community in diverse ways. In this case and relevant to our focus in this paper, the religious communities or societies should be made into research centers of some sort and depository of information. Religious organizations should be involved in setting up this reservoir of knowledge. They are to be encouraged to take research seriously and to give the necessary assistance to researchers in the field to minimize the incidence of mistrust and undesired reactions on the part of respondents. This may only be achieved, in my opinion, if those being studied are made to be aware of the tangible benefits of the study. For example, members of religious organizations could be briefed on how a particular study could improve their spiritual well-being, or in another, their economic wellbeing in order to contribute to the advancement of their religious beliefs.

The subjection of informants or respondents in a research situation involves a form of control. This power is derived from the knowledge gained from the observation of, say the religious systems and values of a society, which are fitted neatly into the researcher's own preconceived categories. A recent example is found in Meyer (1995) who, while discussing the prominent view among Christians in Ghana about "the devil and money", straight away concluded, unconvincingly I suppose, that the link Ghanaians make between "satanic and demonic activities" and money is traced to the poverty of the people. She maintains that "In one way or another most of the stories of satanic and demonic activities are to do with money. In view of the poverty of many Ghanaians this is not astonishing. Many people have financial problems and are looking for ways and means to overcome them" (1995:239). Perhaps the author is ignorant of the fact that this link has little to do with economic prosperity or lack of it, and that it is a cultural phenomenon (part of the religious heritage of Ghanaians). Moreover careful investigation will reveal that this link is not drawn only by the "poor" but also the wealthy of the Ghanaian society. This is an unacceptable example of the researcher forcing his/her 
categorizations onto the situation without establishing any bases (in this case no basis at all) for the viewpoint(s) expressed. It is a credit to Post-modern radical empiricism which pays attention to this unwelcome condition and, therefore, accords the relevant rank to the perceptions of informants without being deterministic. This is made possible by considering the relationship between the researcher and the people under study as one of equality, in which researchers must adopt a policy of openness in their study, and state clearly what they are doing, their objectives and reasons. It is imperative to note, therefore, that knowledge should not be sought only for its own sake, without due consideration to its practical value and power implications.

\section{Conclusion}

The purpose of the discussion in this paper has been to highlight some of the difficulties faced by researchers in their investigation and measurement of religious orientations. Broad areas discussed include theoretical, methodological, and ethical problems associated with social research in general but particularly with religious studies in Africa.

I support the view that the choice and employment of a research method should not take only the epistemological aspects into account but also its suitability to, and the purpose of, the research. Considerations should also be given to the cultural and ideological elements of the community whose value system is to be or being examined. Methodology has vital implications for theory. If the methodology is invalid and unreliable so may be the results of the research making theory seriously hindered. Significantly I urge that quantitatively oriented research which is under-represented in religious studies in Africa be stepped up, in order to reap the vast benefits entailed in the application of such research strategy. Multivariate data analysis does not only allow us to see the broader degree of representativeness of a theory, but also gives us the view of the structural links between dimensions of a particular theory or hypothesis. In the case where the use of only one research technique is bound to give confusing results it may be advisable, finance and time permitting, to use the triangulation of measurement method to curtail, to some degree, incomprehensible results.

The ethical dimension of social research is special since it has to do unrestrictively with the injury and gain of the research to the participants, their right of privacy and confidentiality, their right to be 
informed and to consent, and the social or governmental control over the whole research process. There are guidelines to follow as in any other research. These demands imply accountability of the researcher not only to research sponsoring agencies and to his/her own research community, but also to the local communities (political leaders included) where the researcher might find him/herself working. These demands are vital since they deal with interpersonal relationships and moral issues most of the time.

The awareness of the theoretical, methodological, ideological and ethical dilemmas involved in social research may enhance the work of researchers in their contribution to knowledge and understanding of cultures. There have been calls to take the transcendence and sacred in African thought seriously. This call was followed with the appeal constantly to evolve new ways of studying and viewing African Traditional Religions (ATRs) (Olupona 1991:2). While this was in the context of African culture and indigenous religions, it would not be out of place to extend this appeal to cover other religious forms on the continent. To answer this call needs a reappraisal of the scientific methods that have traditionally been employed to study religions on the continent in order to provide "better and more 'objective' knowledge about them: insights which can claim some improvement in impartiality, representativity and reliability after they have been critically tested, and accepted as for the moment valid knowledge by the global scientific community ..." (Platvoet 1996:129-130).

\section{References}

Aish, Anne-Marie, and Karl G. Jöreskog

1990 A panel model for political efficacy and representativeness: an application of LISREL 7 with weighted least squares. Quality and Quantity 24: 405-426.

Albert, Ethell M.

1968 Value Systems. In: David L. Sills (ed.), International Encyclopedia of the Social Sciences. New York: Macmillan.

Appell, G. N.

1978 Ethical Dilemmas in Anthropological Inquiry: A Case Book. Waltham: Crossroads Press.

Asafo, Dziedzorm $\mathbb{R}$.

1997 Social Class Conversion: Socioeconomic Status of Early Christian Converts in Africa. Nordic Journal of African Studies 6: 81-87.

Brenneman, Walter L., e $r$, Stanley O. Yarian, and Alan M. Olson

1982 The Seeing Eye: Hermeneutical Phenomenology in the Study of Religion. London: Pennsylvania State University Press. 
Barker, Eileen

1981 And ye shall be as gods. In: Religion, Values, and Daily Life: Acts of the $16^{\text {th }}$ Conference, Lausanne 1981. Paris Cedex: CISR.

Barrett, David B.

1982 World Christian Encyclopedia: A Comparative survey of Churches and Religions in the Modern World AD 1900-2000. London: OUP.

Beauchamp, Tom L. et al (eds.)

1982 Ethical Issues in Social Science Research. Baltimore: John Hopkins University Press.

Boruch, Robert F., and Joe S. Cecil, (eds.)

1983 Solutions to Ethical and Legal Problems in Social Research. New York: Academic Press.

Bourdillon, Michael.

1996 Anthropological approaches to the study of African religion. In: Jan Platvoet, James Cox and Jacob Olupona (eds.), The Study of Religions in Africa: Past, Present and Prospects. Cambridge: Roots and Branches. (Religions of Africa, 1)

Brodbeck, May

1968 Readings in the Philosophy of the Social Sciences. New York: Macmillan.

Bryman, Alan

1988 Quantity and Quality in Social Research. London: Unwin Hyman. (Contemporary Social Research Series, 18)

Bulmer, Martin, and Donald P. Warwick (eds.)

1993 Social Research in Developing Countries: Surveys and Censuses in the Third World. London: UCL Press.

Cox, James

1996 Methodological considerations relevant to understanding African indigenous religions. In: Jan Platvoet, James Cox and Jacob Olupona (eds.), The Study of Religions in Africa: Past, Present and Prospects. Cambridge: Roots and Branches. (Religions of Africa, 1)

Glaser, Barney G., and Anselm L. Strauss

1967 The Discovery of Grounded Theory: Strategies for Qualitative Research. Chicago: Aldine.

Graziano, Anthony M., and Michael L. Raulin

1993 Research Methods: A Process of Inquiry. New York: HarperCollins. [ $2^{\text {nd }}$ ed.]

Hair, Joseph F., Jr. et al.

1995 Multivariate Data Analysis With Readings. Englewood Cliffs: Prentice Hall. [ $4^{\text {th }}$ ed.]

Holme, Idar Magne, and Bernt Krohn Solvang

1991 Forskningsmetodik: Om kvalitativa och kvantitativa metoder. Lund: Studentlitteratur.

Hopkins, Raymond F.

1970 Christianity and Sociopolitical Change in Sub-Saharan Africa. In: Marion E. Doro and Newell M Stultz (eds.), Governing in Black Africa: Perspectives on New States. Englewood Cliffs: Prentice-Hall. 


\section{Hoyle, Rick H.}

1995 The Structural Equation Modeling Approach: Basic Concepts and Fundamental Issues. In: Rick H. Hoyle (ed.), Structural Equation Modeling: Concepts, issues, and Applications. London: SAGE.

Hughes, Marie Adele, R. Leon Price, and Daniel W. Mars

1995 Linking Theory Construction and Theory testing: Models with multiple Indicator of latent variables. In: Joseph F. Hair, Jr. et al., Multivariate Data Analysis With Readings. Englewood Cliffs: Prentice Hall. [ $4^{\text {th }}$ ed.]

Inglehart, Ronald

1990 Culture Shift in Advanced Industrial Society. Princeton: Princeton University Press.

Jöreskog, Carr $\mathbb{G}_{\text {. }}$, and Dag Sörbom

1993 LISREL 8: Structural Equation Modeling with the SIMPLIS Command Language. London: Lawrence Erlbaum Associates Publishers.

Kelman, Herbert $\mathbb{C}$.

1982 Ethical Issues in Different Social Science Methods. In: Tom L. Beauchamp et al. (eds.), Ethical Issues in Social Science Research. Baltimore: John Hopkins University Press.

Kimmel, Alan J.

1988 Ethics and Values in Applied Social Research. Newbury Park: SAGE Publications. (Applied Social Research Methods Series, 12)

Lewis-Beck, Michael S.

1980 Applied Regression: An Introduction. Beverly Hills: SAGE Publications. (Quantitative Applications in the Social Sciences, 22)

Lewis, d.R.

1990 Images of traditional African Religions in surveys of World Religions. Religion 20 (3): 311-322.

Mandivenga, Ephraim C.

1991 Resurgence of Islam: Implications for African Spirituality and Dialogue. In: Encounter of Religions in African Cultures; pp. 14-21. Geneva: Lutheran World Federation.

Mbon, Friday

1996 Some Methodological Issues in the academic study of West African Traditional Religions. . In: Jan Platvoet, James Cox and Jacob Olupona (eds.), The Study of Religions in Africa: Past, Present and Prospects. Cambridge: Roots and Branches. (Religions of Africa, 1)

Meyer, Birgit

1992 'If You are a Devil, You are a Witch and, if You are a Witch, You are a Devil.' The integration of 'Pagan' ideas into the conceptual universe of Ewe Christians in Southeastern Ghana. Journal of Religion in Africa 22: 98-132.

1995 'Delivered from the powers of darkness': Confessions of Satanic riches in Christian Ghana. Africa 65 : 236-255.

Miles, Matthew $\mathbb{B}$, and A. Michael Huberman

1984 Qualitative Data Analysis: A Sourcebook of New Methods. London: SAGE Publications. 
Murhpy, d. M.

1990 Black religion and 'black magic': prejudice and projection in images of African-derived religions. Religion 20: 323-337.

Njinya-Mujinya, Leuben

1996 Information Banks in Rural Africa: A Missing Building Block. Nordic Journal of African Studies 5: 118-124.

Olupona, Jacob $\mathrm{K}$.

1991 Major Issues in the Study of African Traditional Religion. In Jacob K. Olupona (ed.), African Traditional Religions in Contemporary Society. New York: Paragon House.

Platvoet, Jan

1996b The religions of Africa in their historical order. In: Jan Platvoet, James Cox, and Jacob Olupona (eds), The Study of Religions in Africa Past, Present and Prospects. Cambridge: Roots and Branches.

Platvoet, Jam, and Jacob $\mathbb{K}$. Olupona

1996 Perspectives on the study of religions in sub-Saharan Africa. In: Jan Platvoet, James Cox, and Jacob Olupona (eds), The Study of Religions in Africa Past, Present and Prospects. Cambridge: Roots and Branches.

Pobee, Hohn S.

1991 A Journey of Exploration into Theology of Religions. In Encounter of Religions in African Cultures. Geneva: Lutheran World Federation.

Riecken, Henry W.

1983 Solutions to Ethical and Legal Problems in Social Research: An Overview. In Robert F. Boruch, and Joe S. Cecil (eds.), Solutions to Ethical and Legal Problems in Social Research. New York: Academic Press.

Ritzer, George

1992 The Sociological Theory. New York: McGraw-Hills, Inc.

Rokeach, Milton

1973 The Nature of Human Values. New York: The Free Press.

Rosenthal $\mathbb{R}$.

1976 Experimental effects in behavioural research. New York: Halsted Press.

Strauss, Anselm L.

1987 Qualitative Analysis For Social Scientists. Cambridge: Cambridge University Press.

Strauss, Anselm L., and Julliet Corbin (eds.)

1997 Grounded Theory in Practice. London: Sage Publications.

Thurstone, L. Leon

1959 The Measurement of Values. Chicago: Chicago University Press.

Truzzi, Marcello (ed.)

1974 Verstehen: Subjective Understanding in the Social Sciences. Philippines: Addison-Wesley Publishing Company.

Westerlund, David

1991 'Insiders' and 'Outsiders' in the Study of African Religions: Notes on Some Problems of Theory and Method. In: Jacob K. Olupona (ed.), 
African Traditional Religions in Contemporary Society. New York: Paragon House.

1993 The study of African religions in retrospect: from "Westernization" to "Africanization". In Jacob Olupona, and S. S. Nyang (eds), Religious Plurality in Africa: Essays in honour of John S. Mbiti. Berlin: Mouton de Gruyter. 